\title{
The Basic Ways for the Masses to Participate in the Leading Cadres Performance Management
}

\author{
Yao-kui Li \\ School of Economics and Management, Taishan University \\ Taian, China
}

\begin{abstract}
In the practice of the current leading cadres performance management, the masses' participation in the leading cadres performance evaluation alone while excluded from other links is not conducive to the realization and improvement of the leadership performance. According to the modern performance management theory, the leading cadres performance management mainly includes leading cadres' mission analysis, performance planning, performance communication and counseling, performance evaluation, performance feedback and the application of evaluation results. Leading cadres and the relevant masses, who should play the principal role in all links of the leading cadres performance management, are a highly performance-related community. In order to ensure that the masses can participate in the leading cadres performance management effectively, the performance supervision departments should keep an open mind of the leading cadres performance management and build a platform for the masses to participate in the leading cadres performance management. The masses, especially the highly performancerelated masses, should participate in the whole process of the leading cadres performance management, and this not only conforms to the performance ecology but also helps to improve the governance capability of our country.
\end{abstract}

Keywords-Mass participation; Leading cadres; Performance management; Participation way

\section{INTRODUCTION}

In the practice of the current leading cadres performance management, the masses can only participate in the leading cadres performance evaluation, and they are always excluded from participating in the other links. This weakens the twoway communication and counseling between leading cadres and the masses, leads to the phenomenon of breaking away from the masses and breaking away from the leaders, and results in poor leadership performance. According to the modern performance management theory, performance evaluation is a link of the performance management, and it will be weak without the support of other links of the performance management. The masses should participate in each link of the leading cadres performance management, and this can help to solve the chaotic phenomenon of the leadership performance such as bureaucracy and formalism. Meanwhile, this will promote the realization and improvement of the leadership performance.

\section{THE THEORY EVIDENCE FOR THE MASSES TO PARTICIPATE IN THE LEADING CADRES PERFORMANCE MANAGEMENT}

Performance management is a dynamic and continuous process of identifying, measuring and developing individual performance and team performance, and in the process these performance should be aligned with the strategic objectives of the organization [1]. Performance management is the extension and development of the traditional performance evaluation. It generally includes mission analysis, performance planning, performance communication and counseling, performance evaluation, performance feedback, the application of performance evaluation results and so on, and these links together constitute a cycle system [2]. Compared with the traditional performance evaluation, performance management is a more complete concept. According to the modern performance management theory, performance evaluation is only a part of the performance management process. Different from traditional performance evaluation, performance management emphasizes the continuous two-way communication between managers and employees, and this can improve the relevant people's behavior and performance [3].

Modern performance management theory holds that performance-related subjects are a performance community, and an orderly community can produce a powerful impetus to eliminate individual inertia [4]. Leadership activities can't be separated from the broad participation of the masses. Leading cadres and the performance-related masses are actually a performance community with common interests. The essence of the masses' participation is to mobilize all relevant resources. This helps to form a performance community and a group motive force, and the group motive force can eliminate individual inertia. All these can promote the realization of the common goals of the performance-related subjects.

\section{THE BASIC WAYS FOR THE MASSES TO PARTICIPATE IN THE LEADING CADRES PERFORMANCE MANAGEMENT}

According to the modern performance management theory, the leading cadres performance management mainly includes leading cadres' mission analysis, performance planning, performance communication and counseling, performance evaluation, performance feedback and the application of evaluation results. The masses' participating in the leading cadres performance management means that the performance- 
related masses should participate in all links of the leading cadres performance management.

\section{A. The Masses should Participate in the Analysis of Leading Cadres' Mission}

Analyzing the leading cadres' mission is the basis of formulating the leading cadres' performance plans. This link is to analyze the internal and external environment that the leading cadres face, which can help the leading cadres understand their mission. And it can provide a basis for the implementation of the leading cadres performance management. "All for the masses" is the basic starting point of the leading cadres' work. Leading cadres must take safeguarding the masses' interests as the fundamental starting point and foothold of the leadership activities. As Mao Zedong said, "to connect with the masses, we must follow the needs and wishes of the masses. Here are two principles: one is the actual needs of the masses, not the needs fantasized in our minds; the other is the voluntary determination of the masses, the determination should be made by the masses themselves rather than by us instead of the masses [5] ". "We should pay close attention to the problems in the people's life, from land and labor to firewood, rice, oil and salt. We should let them understand the higher tasks that we have proposed from these things [6]". In short, leaders at all levels should regard the real needs and wishes of the masses as their mission.

\section{B. The Masses should Participate in the Formulation of the Leading Cadres' Performance Plans}

Performance management departments must collect all kinds of performance information when they formulate the leading cadres' performance plans. The masses are a group with strong initiative, and the leading cadres' performance objects will be difficult to achieve without their cooperation. Therefore, the masses should be the key information source for the leading cadres' performance plans. Performance management departments must communicate with the performance-related masses when they analyze the performance goals, performance dimensions, key performance indicators, performance standards and performance cycle. The relevant departments, especially the performance supervision departments, should communicate fully with the masses and leading cadres. And the relevant departments should dynamically evaluate the reliability and validity of the leading cadres performance indicators so as to maintain a high consistency between the leading cadres' performance objectives and the masses' needs. All these can help to provide the basic guarantee for the implementation of the leading cadres' performance plan and performance evaluation.

\section{The Masses should Participate in the Leading Cadres' Performance Communication and Counseling}

The performance communication and counseling between the leading cadres and the relevant masses should run through the whole process of the leading cadres performance management. It can't be ignored that the leaders are not omnipotent and they also need communication and counseling. The leading cadres will lose their followers and influence without the masses' participation, and even they will lose their authority. So, the leading cadres should establish the concept of performance community and pay attention to strengthening the performance communication with the highly performancerelated masses. Meanwhile, a performance coordination mechanism should be built among the relevant subjects.

\section{The Masses should Participate in the Leading Cadres' Performance Evaluation}

The performance management departments should establish the concept of trusting and relying on the masses when they evaluate the leading cadres' performance. The relevant departments should respect the subjects position of the masses. The masses' participating in the leading cadres' performance evaluation reflects the masses' right to supervise the leading cadres' performance. At the same time, the masses' participating can ensure that the leading cadres' performance evaluation is more authentic and effective.

\section{E. The Masses should Participate in the Leading Cadres' Performance Feedback}

At the end of the leading cadres performance cycle, performance feedback interviews should be carried out according to the results of the leading cadres' performance evaluation. The relevant departments of the leading cadres performance management should organize the masses, especially those related to the leading cadres' performance, to participate in the performance feedback process. The masses' participating can urge the leading cadres to improve their quality and ability continuously. Through feedback communication, the relevant subjects can understand the shortcomings in the leading cadres' performance and work out performance improvement plans together.

\section{F. The Masses should Participate in the Application of the Leading Cadres' Performance Evaluation Results}

The results of the leading cadres' performance evaluation are not only used for performance improvement but also as the main basis for the leading cadres' job adjustment. The leading cadres management departments should gradually improve the leading cadres selection system based on their performance and let the masses participate in the whole process. Selecting the leading cadres should be based mainly on the results of the leading cadres' performance evaluation, and it should be guided by the needs of the masses. In short, the source of the leading cadres' power and interests should be highly related to the masses.

\section{THE RESTRICTIVE FACTORS THAT THE MASSES FACE WHEN THEY PARTICIPATE IN THE LEADING CADRES PERFORMANCE MANAGEMENT AT PRESENT}

\section{A. The Closed Concept of the Performance Management}

At present, the leading cadres performance management is still dominated by the closed management concept based on control. This kind of concept excludes the relevant masses from participating in the whole process of the leading cadres performance management, making the leading cadres performance management fragmented. Such exclusion is 
mainly manifested in the following two aspects. Firstly, the relevant subjects of the leadership activities are independent, and there is no effective performance coordination mechanism and interests association mechanism between the leading cadres and the masses. Secondly, the performance-related masses can only participate in part of the leading cadres performance management, so it is difficult to form a sense of performance community. Leadership activities need the masses' participation, and neglecting the masses' ability and their subjects position has caused misunderstanding and even conflicts between the masses and the leading cadres in reality.

\section{B. The Correlation Degree of the Masses Who Participate in the Performance Management isn't High}

The low correlation is mainly manifested in the following aspects. Firstly, the masses arranged to participate in the leading cadres performance management may not be sensitive to the leadership performance in practice. Secondly, The key stakeholders may be totally excluded. The relevant departments are often arbitrary in choosing who and how to participate in the performance management. They may even choose some people who are good at saying good words. Thirdly, the masses only play the role of "just for show". Obviously, this is actually formalism, and it often makes the masses think that the government is playing games.

\section{The Masses can only Partially Participate in the Leading Cadres Performance Management}

That the masses participate in the leading cadres performance management has existed for a long time in the management practice, but the masses often can only participate in the performance evaluation. They are always excluded from participating in the other links. This can't help to realize and improve the leading cadres' performance.

\section{The Technology of the Traditional Leading Cadres Performance Management is Lagging behind}

Diversification of social stakeholders brings more difficulties to the effective leadership activities. In the current implementation process of the leading cadres performance management, the implementers are mainly the evaluation groups organized by the performance supervision departments, which is no longer suitable for the current complex leadership environment.

\section{E. Laws and Regulations for the Leading Cadres Performance Management are Absent}

At present, there is no relatively specific reward and punishment measures for the leading cadres whether or not they have completed the performance plan in a certain term of office or a performance cycle. Relevant regulations on rewards and punishments for the leading cadres haven't paid enough attention to the performance concerned by the masses, and scientific laws and regulations for the leading cadres performance management haven't yet been established. This is also an important reason for the "performance disorder" such as the formalization existing in the current leading cadres performance management.

\section{THE BASIC GUARANTEE FOR THE MASSES TO PARTICIPATE IN THE LEADING CADRES PERFORMANCE MANAGEMENT}

\section{A. Keeping an Open Mind in the Leading Cadres Performance Management}

The closure of the leadership concept is essentially the closure of the information communication channels. At present, the information dissemination channels among all the social strata are relatively smooth. The mystery of the socalled elite strata is becoming more and more weakened. The independence and autonomy of the masses have gradually improved, and a new contradiction has formed between the closeness of the leading cadres' governance concept and the open consciousness of the masses. Only an open leading cadres performance management system can respond to the masses' demands and bring all the related people into the leading cadres performance management. And this can help to promote the realization and improvement of the leadership performance.

\section{B. Strengthening the Correlation Degree of the Masses Who Participate in the Performance Management}

In fact, the relevant departments has also paid attention to the participation of the masses in the management practice, but the correlation degree of the participants is often too low. The specific meaning of the masses in practice should refer to the stakeholders or the performance stakeholders within a certain range. The masses, especially the masses involved in the leadership activities, often have more performance sensitivities than the leading cadres. The relevant departments should strengthen their direct participation in the leadership activities. In short, The relevant departments should pay more attention to the people's dominant position in serving the people. When necessary, the highly performance-related masses should be allowed to participate in the leadership activities directly.

\section{The Performance-related Masses should Participate in the Whole Process of Leading Cadres Performance Management}

It is necessary to ensure that the performance-related masses participate in the whole process of the leading cadres performance management. The relevant departments should change the masses' traditional role of the supervisors into the role of the participants, this helps to make the leading cadre performance information spread among the performancerelated masses, and this can help to promote the realization and improvement of the leading cadres performance.

\section{Building a Platform for the Masses to Participate in the Leading Cadres Performance Management}

A collaborative platform based on network information technology should be built for the masses to participate in the leading cadres performance management. The collaborative platform focuses on leadership performance activities, and the performance-related masses should participate in the management activities. And the collaborative platform will help the performance-related subjects build a network-type organization system with a common mission. 
E. Establishing and Perfecting Laws and Regulations for the Masses to Participate in the Leading Cadres Performance Management

The relevant departments should strengthen the formulation and implementation of the laws and regulations for the masses to participate in the leading cadres performance management, and they should ensure that the masses' participating in the management activities is carried out within the laws and regulations. The laws and regulations can provide a basic support for the masses to directly participate in the leading cadres performance management.

\section{CONCLUSIONS}

Aiming at the phenomenon of breaking away from the masses and breaking away from the leaders in the current leading cadres performance management, this paper put forward the basic ways for the masses to participate in the leading cadres performance management. On the basis of modern performance management theory, the leading cadres and the masses were regarded as a benefit-related performance community, and the masses should participate in all links of the leading cadres performance management. This helps to form a group dynamic mechanism, which can not only supervise the leadership performance but also provide necessary supports for the leadership activities. The masses' participating in the leading cadres performance management is conducive to forming an open leading cadres performance management system. It also helps to solve the problems of formalism, bureaucracy, hedonism and luxury. At the same time, it can make the leading cadres change their working mechanism and working style, and it can help to improve the state governance capability.

\section{REFERENCES}

[1] Herman Aguinis, Performance Management, 3rd ed., (Translators: Xin Liu, Maochang Chai, Yao Sun) China Renmin University Press, Beijing, 2013, p.4. (In Chinese)

[2] Qinxuan Gu, Performance Management, 3rd ed., Shanghai Jiaotong University Press, Shanghai, 2015, p.10.

[3] Qinxuan Gu, Performance Management, 3rd ed., Shanghai Jiaotong University Press, Shanghai, 2015, pp.10-11.

[4] Xiaoqing Liao, Jiahan He, Design and Implementation of Employee Performance Management System, South China University of Technology Press, 2002, p.5.

[5] Mao Zedong, "The United Front in Cultural Work", The Selected Works of Mao Zedong, vol.3, People's Publishing House, 1991, pp.1012-1013.

[6] Mao Zedong, "Be Concerned with the Well-being of the Masses and Pay Attention to Methods of Work", The Selected Works of Mao Zedong, vol.1, People's Publishing House, 1991, pp.136-137. 